\title{
First-principle algorithm for air quality electrochemical gas sensors
}

\author{
Bin Ouyang1,* \\ ${ }^{1}$ Lancaster Environment Centre, Library Avenue, Lancaster University, Lancaster LA1 4YQ the United Kingdom \\ * Corresponding author. b.ouyang1@lancaster.ac.uk
}

KEYWORDS: Electrochemical sensor, algorithm, temperature, relative humidity, air quality

\begin{abstract}
We report here a simple approach that allows for rapid mapping of raw voltage readings to concentrations for part-per-billion level air quality electrochemical sensors. The key step is the introduction of an auxiliary sensor and cover it with a thin Nafion membrane, one that is well-known for its both highly efficient and selective permeation of water vapor. This sensor captures any signal that is induced by changes of relative humidity, and such signal can then be used to rapidly correct for drifts of the main sensor which sees both the target gas and ambient water vapor. The whole process is entirely based on first principle, preserves physical clarity, is very amenable for implementation by routine sensor users and delivers data that compare favorably with reference instruments. We also suggest that this double-sensor setup be further condensed into one sensor in which one of the electrodes is coated by Nafion and exposed to ambient air in the same way as the normal sensing electrode.
\end{abstract}

Air pollution poses great threat to environmental sustainability and human health on a global scale ${ }^{1}$. The need to understand air quality in highly confined spaces such as the indoor environment ${ }^{2-3}$ or where sharp spatio-temporal gradients exist due to altitude or proximity to emission sources such as industrial plants ${ }^{4-5}$ and urban streets ${ }^{6}$, and to accurately quantify personal exposure levels for better assessment of health impacts of air pollution ${ }^{7-8}$, has prompted the use of small but ultra-sensitive gas sensors in monitoring key gaseous pollutants such as $\mathrm{NO}, \mathrm{NO}_{2}, \mathrm{CO}, \mathrm{SO}_{2}$ and $\mathrm{O}_{3} 9-12$. Through gradual accumulation of data from tests performed under a broad range of ambient conditions, however, doubts about this technique were also mounting since many colocation studies have revealed that they can report data that show very poor correlation $\left(R^{2}<0.5\right)$ with reference 13-15. This challenges the use of small sensors in the field, limits its role to provide only indicative information ${ }^{14}$, and frustrates end-users in the long run inevitably ${ }^{16}$.

The core problem here is that sensors respond to $T$ and RH changes, which vary in the field environment all the time, generating interfering signals that are often large enough to fully scavenge target gas signal. To eliminate such effects, models of varying levels of complexities have been exploited, including univariable to multivariable linear regression methods that aim to describe the effects of $T$ and $\mathrm{RH}$ through linear to higher-order terms ${ }^{17-21}$. More recent studies also speculated that sensor response to $T$ and $\mathrm{RH}$ may be very complex, occurring through processes that can be nonlinear, and have applied more advanced algorithms such as the Random Forest Regression and others based on Machine Learning 19, 22-24, Artificial Neural Networks 25-27, or the High-Dimensional Model Representation approach designed by Aerodyne and Princeton 28. Mapping schemes (that link sensor raw reading with concentration) afforded by these above approaches can be unamenable for interpretation, may include terms that are noncausal ${ }^{29}$, and often offer limited insights into the actual governing physical parameters.

\section{EXPERIMENTAL SECTION}

Four randomly chosen $\mathrm{NO}_{2}$-B43F electrochemical sensors (Alphasense, UK), with sensitivity reaching part-perbillion (ppb) levels, were used to measure ambient $\mathrm{NO}_{2}$ in an urban environment in Shenzhen, China. These sensors were housed in a custom-built instrument enclosure together with necessary electronics. Voltage readings from the working and auxiliary electrodes of the sensors were sampled and averaged to every twenty seconds.

For inter-comparison, a reference instrument (Model 42i, Thermo-Fisher Scientific) was also deployed at the same site and measured ambient $\mathrm{NO}_{2}$ at 1 min time resolution.

\section{RESULTS AND DISCUSSION}

Figure 1 shows the data from two such sensors, calculated as the difference between their working and scaled $(\times 1.6)$ auxiliary electrode readings to remove by a large part the $T$ induced drifts for both sensors, followed by some rebasing so that the two readings appear on the same scale. For most such sensors we have tested, a scaling factor of $1.4-1.8$ is often required to fully remove the $T$-effect on working electrode using its auxiliary counterpart, and the fact that it normally tends to be greater than 1 may reflect their different sizes based on the sensor design. Both sensors were then deployed outdoor without any active $T$ or RH stabilization. Sensor A is a non-modified one, while sensor B has had its sensing surface covered by a thin film of the Nafion membrane (thickness $25 \mu \mathrm{m}$ ), one that is well known for its selective permeation of water vapor but not $\mathrm{NO}_{2}{ }^{30}$. This special feature of the Nafion membrane suggests that sensor $\mathrm{B}$ can act as a spectator that monitors RH-related signal only, 
while sensor A monitors both this and the signal that is caused by ambient $\mathrm{NO}_{2}$. The patterns of the data from the two sensors and that from the reference $\mathrm{NO}_{2}$ instrument indeed verified this, as signal from sensor $\mathrm{A}$ is a clear superposition of the last two (with some rebasing and scaling). It is also noteworthy that the addition of the membrane does not pose significant diffusion barrier for water vapor, since the two sensors appear to respond synchronously and by similar magnitude to RH changes, as is shown in Figure 1.

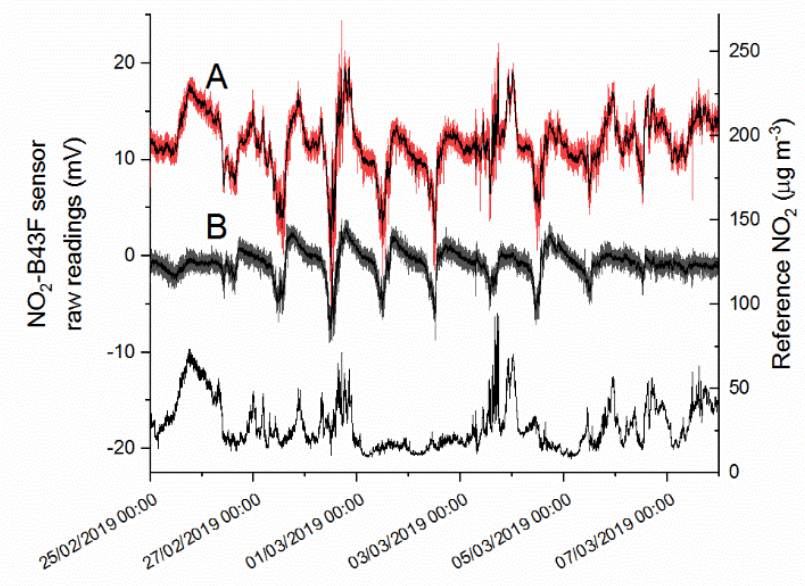

Figure 1 Raw sensor reading shown as a clear superposition of gas and relative humidity transient signals. Signal readings (upper two curves) from two randomly picked Alphasense $\mathrm{NO}_{2}$-B43F sensors A (unmodified) and B (with a $25 \mu \mathrm{m}$ thick Nafion membrane added to seal its front sensing face). Also shown is the $\mathrm{NO}_{2}$ concentration time series (bottom curve) measured by the reference Thermo-Fisher $\mathrm{NO}_{\mathrm{x}}$ analyser (Model 42i). It is readily observable that the signal curve from sensor $A$ is a composite of that from sensor $B$ and that of the $\mathrm{NO}_{2}$ signal from the reference instrument. Temperature range was $14.7-34.4{ }^{\circ} \mathrm{C}$ during this period.

Bearing in mind that signal B is RH-related, we are now in a good position to examine its origin (i.e. how it is related to RH changes) in the dynamic field environment. Firstly, little correlation can be found between signal B and RH, T or auxiliary electrode (AE) reading, or their quadratic or cross product terms. In other words, none of these terms can adequately represent signal B. Secondly, time series of signal $\mathrm{B}$ and that of the $\mathrm{RH}$ transient, $\Delta \mathrm{RH} / \Delta t$, show clear similarity when the latter was smoothed, as shown in Figure 2, except some temporal delay in between (around $10 \mathrm{mins}$ ). This suggests that RH transient can be the cause of signal B, and indeed our numerous field tests have consistently confirmed this. Establishment of causality is further supported by observations of both the sensor manufacturer ${ }^{31}$ and two other independent groups ${ }^{20,32}$ in step changes of RH under well-controlled lab conditions at relatively stable $T$. We are unsure if $T$ has any effect on the sensor response to RH transient, and further laboratory studies are needed if this is to be elucidated.

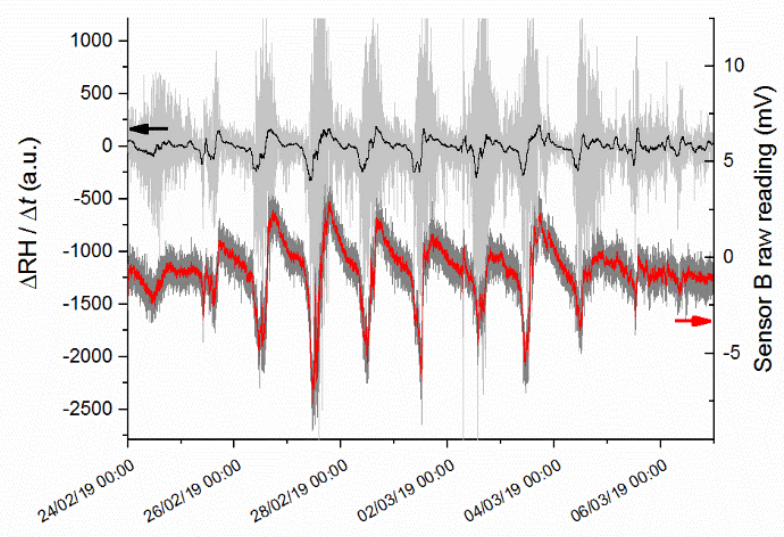

Figure 2 The close resemblance of the auxiliary sensor signal to the calculated ambient RH transient. $\Delta \mathrm{RH} / \Delta \mathrm{t}$, calculated as the derivative of $\mathrm{RH}$ against time and then smoothed by 256 pts adjacent averaging (left axis), and the signal reading from the auxiliary sensor $\mathrm{B}$ (Alphasense $\mathrm{NO}_{2}$-B43F sensor covered by a Nafion membrane, right axis). Good correspondence can be observed.

We have further examined the possibility of reconstructing signal $\mathrm{B}$ from $\Delta \mathrm{RH} / \Delta t$. With several complicating factors as stated above (the need to smooth, the temporal delay, some potential $T$-dependence as noted above, and possibly other terms that are less visible), this turned out to be more difficult than it seems. Mueller et al. ${ }^{20}$ have made similar mathematical attempts but concluded also that the errors in simulated results can still critically control measurement accuracy across various timescales (minutes to hours). We suspect that detailed functional form linking sensor response with $\Delta \mathrm{RH} / \Delta t$ may have not been fully understood. Addition of the "spectator" sensor B thus provides a convenient way to overcome/bypass this technical difficulty, allowing the $\mathrm{RH}$ transient induced signal to be measured straightaway.

It is interesting to compare the roles of the auxiliary electrode, one that was added in the sensor by the manufacturer some ten years ago, with that of sensor B. The former is embedded deep in the sensor and experiences similar $T$ changes as the working electrode. It can therefore be regarded as a tracker of any $T$-induced changes and allows these to be removed readily. On the other hand, it is not in contact with ambient air, as otherwise it measures the target gas too, and for this exact reason the auxiliary electrode in the current sensor setup does not sense RH changes in the environment. Sensor B makes up this drawback and effectively serves as a tracker of the RH transient induced signal. Subtraction of this signal from that of the working sensor, which sense both the target gas $\mathrm{NO}_{2}$ and the $\mathrm{RH}$ transient induced signal, gives largely the $\mathrm{NO}_{2}$ signal. This approach is somewhat counter-intuitive, as for electrochemical sensing that suffers from cross-interference $\mathrm{CH}_{2} \mathrm{O}$ vapor in this case can be effectively regarded as an "interferent", although we note that $\mathrm{H}_{2} \mathrm{O}$ does not affect voltage reading of the working electrode through redox reactions.), it is a more common and natural practice to remove the interfering rather than target gas. The price we pay here is an 
extra $\mathrm{NO}_{2}$ sensor, which in most cases is affordable. The magnitude of random noise will also be amplified by a factor of $\sqrt{2}$, since we have used one sensor to correct for the other, but this is usually tolerable in most small sensor applications and can be reduced by averaging when needed.

Following this line of thinking, we have used the following expression to calculate $\mathrm{NO}_{2}$ concentration $\left[\mathrm{NO}_{2}\right.$ ] from sensor raw readings.

$$
\left[\mathrm{NO}_{2}\right](t)=\left(W E_{\mathrm{A}}(t)-a * A E_{\mathrm{A}}(t)-b * \operatorname{Sensor}_{\mathrm{B}}(t)-c\right) / s
$$$$
\text { Equation } 1
$$

where $W E_{\mathrm{A}}$ is sensor $\mathrm{A}$ working electrode reading, $A E_{\mathrm{A}}$ is sensor A auxiliary electrode reading and Sensor ${ }_{B}$ is sensor $\mathrm{B}$ raw reading given by $\left(W E_{\mathrm{B}}-A E_{\mathrm{B}}\right)$. All these are observables and vary with time $t$. Coefficients $a$ and $b$ provide the necessary scaling that account for any small differences among electrodes in their response to $T$ and $\mathrm{RH}$ transient changes, respectively, coefficient $c$ provides the necessary rebasing, while $s$ is the sensitivity coefficient for sensor A. In addition, we have sometimes noticed that a third term, namely temperature transient $\Delta T / \Delta t$, needs to be included in Equation 1 to improve the fit for the Alphasense $\mathrm{NO}_{2}$ $\mathrm{B} 43 \mathrm{~F}$ sensors. This is caused by the sensor electrodes responding not only to $T$ but also $\Delta T / \Delta t$, making $A E_{\mathrm{A}}$ a mixture of both effects. Rather occasionally, working and auxiliary electrodes even of the same sensor can have highly disproportionate responsivity to $T$ and $\Delta T / \Delta t$, making subtraction of these two $T$-related effects through adjustment of a single parameter $a$ insufficient. The \#4 sensor in Figure 3 shows one such example in which some deviating values of sensor $\left[\mathrm{NO}_{2}\right]$ from reference are clearly caused by such effect and the quality of fit can be further improved through inclusion of the temperature transient term.

Sensors to be calibrated can then be deployed outdoor, an environment where $T$ and $\mathrm{RH}$ change continuously, together with a reference $\mathrm{NO}_{2}$ instrument which provides continuous measurements of $\left[\mathrm{NO}_{2}\right]$. Multivariable linear regression of [ $\left.\mathrm{NO}_{2}\right]$ against $W E_{\mathrm{A}}, A E_{\mathrm{A}}$ and Sensor $\mathrm{B}$ will then allow coefficients $a, b, c$ and $s$ to be determined simultaneously. Calibration should preferably be performed in an environment where both $A E_{\mathrm{A}}$ and Sensor $\mathrm{B}$ vary substantially, one that would allow their associated coefficients $a$ and $b$ to be determined with high confidence. Given the strong $T$ dependence of $A E_{\mathrm{A}}$ and Sensor $\mathrm{B}_{\mathrm{B}}$ it is conceivable that calibration should best be performed in a warm rather than cold environment, with $T_{\max }$ being comparable or ideally higher than that in the actual deployment period. We often noted that calibration results thus obtained were more robust than vice versa, for reasons above. Meanwhile, calibration strategy will continue to develop as an active area of research and may best be decided by sensor users who know the application conditions and purposes more thoroughly.

We show below results from both the four Alphasense $\mathrm{NO}_{2}$-B43F sensors and the reference $\mathrm{NO}_{2}$ instrument, sampling ambient air for two months. $T$ and $\mathrm{RH}$ have been measured by a Bosch BME280 sensor to be within $12.4-35.4{ }^{\circ} \mathrm{C}$ and $19.6 \%$ - 90.0\%, respectively. Four other $\mathrm{NO}_{2}$-B43F sensors were modified as described above, forming four [1+1] pairs with the unmodified sensors. All unmodified sensors were then calibrated using reference $\left[\mathrm{NO}_{2}\right]$ in the initial eight days, determining the various coefficients in Equation 1 , which were then used to convert sensor raw signal to $\left[\mathrm{NO}_{2}\right]$ in the following seven weeks (free-run period). This is what to be expected in real world applications, i.e. calibrating sensors with reference data for a short period followed by longer-term field deployment.

Time series data from both the reference instrument and the four sensors are shown in Figure 3 on the left, while correlation plots are shown on the right. Good correlation is clearly visible, and further suggested by the common statistics metrics such as $R^{2}$ (CoD, Coefficient of Determination) and RMSE (Root Mean Square Error) from the linear fits of sensor data against the reference one. 

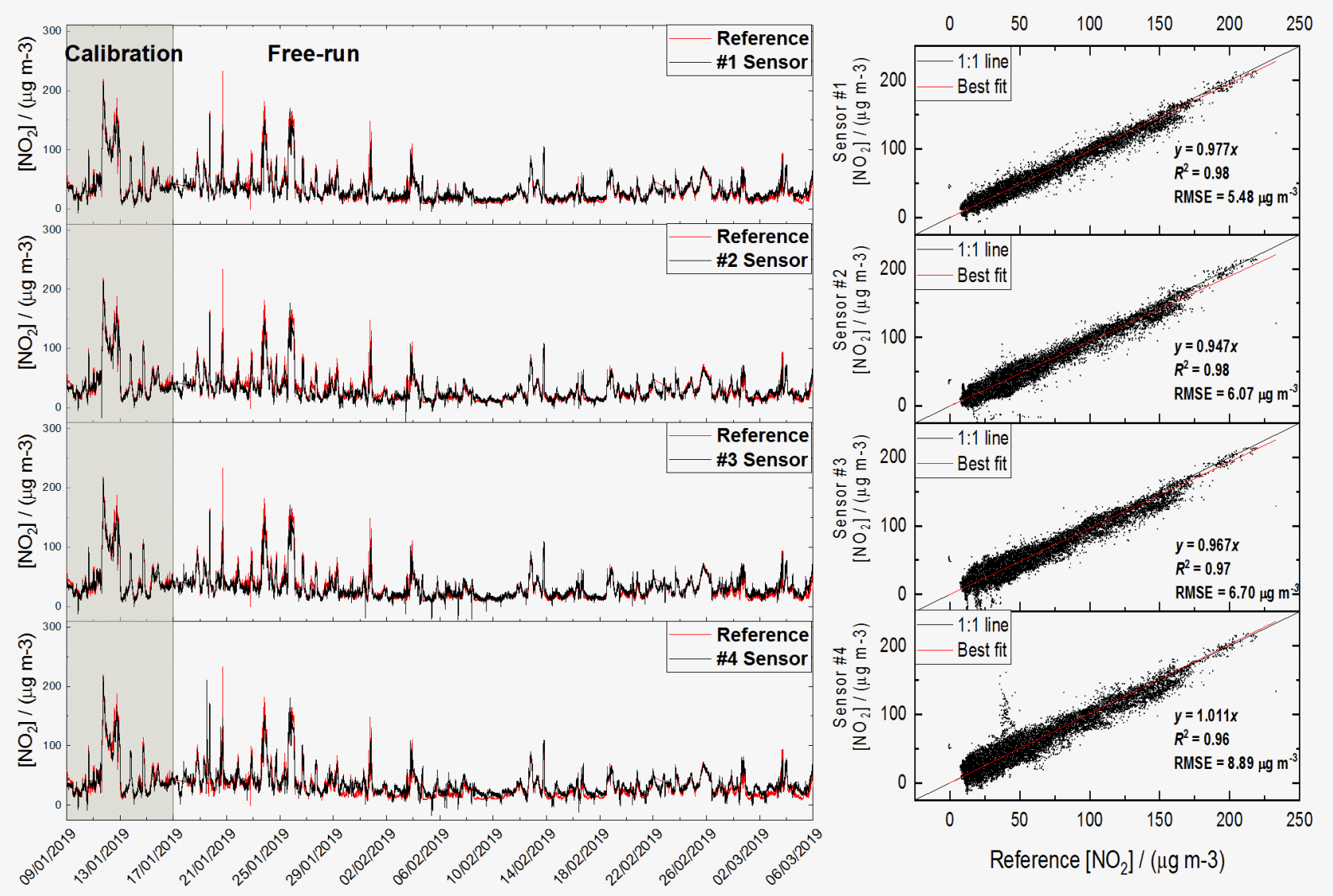

Figure 3 Validation of sensor $\mathrm{NO}_{2}$ data. Time series of $\mathrm{NO}_{2}$ from four randomly selected and calibrated $\mathrm{NO}_{2}$ - $\mathrm{B} 43 \mathrm{~F}$ sensors deployed outdoor and co-located with a reference instrument. Sampling interval of the reference instrument is 1 min and that of the sensors is 20 seconds. Sensor data were then smoothed through 15 pts averaging to achieve comparable Signal to Noise ratio as that of the reference instrument. Temperature during the calibration period was $13.8-30.8{ }^{\circ} \mathrm{C}$ and that during the free-run period was $12.4-$ $35.4^{\circ} \mathrm{C}$.

So far, we have seen all electrochemical sensors detecting the most common polluting gases including $\mathrm{CO}, \mathrm{NO}, \mathrm{O}_{3}$ and $\mathrm{SO}_{2}$ are all responsive to $\mathrm{RH}$ transient. The current method can therefore be applied to these other sensors so long as the target gases remain impermeable through the Nafion membrane. All gases listed above satisfy this criterion, and our tests have proven that it is viable to correct for $T$ and $\mathrm{RH}$ effects for these other gas sensors too.

We end by suggesting a way to improve the compactness of the system, namely by adding an extra electrode coated/covered by Nafion into the original sensor. This electrode should be placed close to sensor surface as the normal working electrode, but the Nafion coating would allow it to track only the RH transient signals. This would not only reduce the cost but also improve system portability, which is often important in cases such as personal exposure measurements or on mobile platforms such as Unmanned Aerial Vehicles (UAVs).

\section{CONCLUSIONS}

To summarize, state-of-the-art electrochemical sensors respond to $\Delta \mathrm{RH} / \Delta t$ instead of $\mathrm{RH}$, and furthermore they act as a "shock absorber" of such changes and release the effect in a delayed manner. This unusual behavior has made RHrelated sensor drift extraordinarily difficult to capture and simulate. Many advanced algorithms that were invoked to tackle such issue lack physical clarity, and the solutions they offer vary greatly from model to model which will almost certainly lead to great methodological divergence in the future. With minor sensor modification, we propose here a much simpler solution to solve the problem, which is generic and easy to implement and, because all fitting terms have definite physical meanings, any fit anomaly spotted can be diagnosed readily. We believe this current work will help unify sensor calibration methods, improve sensor data quality and furthermore facilitate their use in forming highdensity air quality monitoring networks or performing personal exposure measurements of various kinds and purposes.

\section{AUTHOR INFORMATION}

\section{Corresponding Author}

*b.ouyang1@lancaster.ac.uk

\section{Acknowledgments}


We wish to thank the three anonymous reviewers for their constructive comments on the manuscript which greatly help to improve it. We also express our great thanks to Mr. Hui (Roger) Li from Shenzhen Haneda Precision Electronics Co., Ltd for his kind support of some of our experimental work.

\section{Competing Interests}

The approach and proposed sensor design described in this article have been submitted as part of the application "Instrument, method and sensor for monitoring of gas concentrations" for the Chinese as well as international patents under the $\mathrm{Pa}$ tent Cooperation Treaty (PCT).

\section{REFERENCES}

1. WHO, Ambient air pollution: A global assessment of exposure and burden of disease. 2016.

2. Ezzati, M.; Kammen, D., The health impacts of exposure to indoor air pollution from solid fuels in developing countries: knowledge, gaps, and data needs. Environ. Health Perspect. 2002, 110 (11), 1057-1068.

3. Tham, K. W., Indoor air quality and its effects on humans-A review of challenges and developments in the last 30 years. Energy and Buildings 2016, 130, 637-650.

4. Bauleo, L.; Bucci, S.; Antonucci, C.; Sozzi, R.; Davoli, M.; Forastiere, F.; Ancona, C., Long-term exposure to air pollutants from multiple sources and mortality in an industrial area: a cohort study. Occup Environ Med 2019, 76, 48-57.

5. Ojekunle, Z. O.; Jinadu, 0. O. E.; Afolabi, T. A.; Taiwo, A. M., Environmental Pollution and Related Hazards at Agbara Industrial Area, Ogun State. Scientific Reports 2018, 8, 6482.

6. Mead, M.; Popoola, O.; Stewart, G.; Landshoff, P.; Calleja, M.; Hayes, M.; Baldovi, J.; McLeod, M.; Hodgson, T.; Dicks, J.; Lewis, A.; Cohen, J.; Baron, R.; Saffell, J.; Jones, R., The use of electrochemical sensors for monitoring urban air quality in lowcost, high-density networks. Atmos. Environ. 2013, 70, 186-203.

7. Harrison, R. M.; Thornton, C. A.; Lawrence1, R. G.; Mark, D.; Kinnersley, R. P.; Ayres, J. G., Personal exposure monitoring of particulate matter, nitrogen dioxide, and carbon monoxide, including susceptible groups. Occupational \& Environmental Medicine 2002, 59, 671-679.

8. Larkin, A.; Hystad, P., Towards Personal Exposures: How Technology Is Changing Air Pollution and Health Research. Curr Environ Health Rep. 2017, 4 (4), 463-471.

9. Lung, S. C.; Jones, R.; Zellweger, C.; Karppinen, A.; Penza, M.; Dye, T.; Hüglin, C.; Ning, Z.; Lewis, A. C.; Schneidemesser, E. v.; Peltier, R. E.; Leigh, R.; Hagan, D.; Laurent, O.; Carmichael, G.; Beig, G.; Cohen, R.; Cross, E.; Gentner, D.; Gerboles, M.; Khan, S.; Kroll, J.; Mudu, P.; Carceller, X. Q.; Ruggeri, G.; Smith, K.; Tarasova, O. Lowcost sensors for the measurement of atmospheric composition: overview of topic and future applications World Meteorological Organization: 2018.

10. Kumar, P.; Morawska, L.; Martani, C.; Biskos, G.; Neophytou, M.; Sabatino, S. D.; Bell, M.; Norford, L.; Britter, R., The rise of low-cost sensing for managing air pollution in cities. Environment International 2015, 75, 199-205.

11. Baron, R.; Saffell, J., Amperometric gas sensors as a low cost emerging technology platform for air quality monitoring applications: a Review. ACS Sens. 2017, 2, 1553-1566.

12. Snyder, E. G.; Watkins, T. H.; Solomon, P. A.; Thoma, E. D.; Williams, R. W.; Hagler, G. S.; Shelow, D.; Hindin, D. A.; Kilaru, V. J.; Preuss, P. W., The changing paradigm of air pollution monitoring. Environ Sci Technol 2013, 47 (20), 11369-77.

13. Lewis, A. C.; Lee, J. D.; Edwards, P. M.; Shaw, M. D.; Evans, M. J.; Moller, S. J.; Smith, K. R.; Buckley, J. W.; Ellis, M.; Gillot, S. R.; White, A., Evaluating the performance of low cost chemical sensors for air pollution research. Faraday Discuss. 2016, 189, 85-103.

14. Castella, N.; Dauge, F. R.; Schneider, P.; Vogt, M.; Lerner, U.; Fishbain, B.; Broday, D.; Bartonova, A., Can commercial low-cost sensor platforms contribute to air qualitymonitoring and exposure estimates? Environment International 2017, 99, 293-302.

15. Jiao, W.; Hagler, G.; Williams, R.; Sharpe, R.; Brown, R.; Garver, D.; Judge, R.; Caudill, M.; Rickard, J.; Davis, M.; Weinstock, L.; Zimmer-Dauphinee, S.; Buckley, K., Community Air Sensor Network (CAIRSENSE) project: evaluation of low-cost sensor performance in a suburban environment in the southeastern United States. Atmos. Meas. Tech. 2017, 10, 3575-3588.

16. Rai, A. C.; Kumar, P.; Pilla, F.; Skouloudis, A. N.; Sabatino, S. D.; Ratti, C.; Yasar, A.; Rickerby, D., End-user perspective of lowcost sensors for outdoor air pollution monitoring. Science of The Total Environment 2017, 607, 691-705.

17. Wei, P.; Ning, Z.; Ye, S.; Sun, L.; Yang, F.; Wong, K. C.; Westerdahl, D.; Louie, P. K. K., Impact Analysis of Temperature and Humidity Conditions on Electrochemical Sensor Response in Ambient Air Quality Monitoring. Sensors 2018, 18.

18. Sun, L.; Wong, K. C.; Wei, P.; Ye, S.; Huang, H.; Yang, F.; Westerdahl, D.; Louie, P. K. K.; Luk, C. W. Y.; Ning, Z., Development and Application of a Next Generation Air Sensor Network for the Hong Kong Marathon 2015 Air Quality Monitoring. Sensors 2016, $16(2), 211$.

19. Zimmerman, N.; Presto, A. A.; Kumar, S. P. N.; Gu, J.; Hauryliuk, A.; Robinson, E. S.; Robinson, A. L.; Subramanian, R., A machine learning calibration model using random forests to improve sensor performance for lower-cost air quality monitoring. Atmos. Meas. Tech. 2018, 11, 291-313.

20. Mueller, M.; Meyer, J.; Hueglin, C., Design of an ozone and nitrogen dioxide sensor unit and its long-term operation within a sensor network in the city of Zurich. Atmos. Meas. Tech. 2017, 10, 3783-3799.

21. Mijling, B.; Jiang, Q.; Jonge, D. d.; Bocconi, S., Field calibration of electrochemical $\mathrm{NO}_{2}$ sensors in a citizen science context. Atmos. Meas. Tech. 2018, 11, 1297-1312.

22. De Vito, S.; Esposito, E.; Salvato, M.; Popoola, O.; Formisano, F.; Jones, R.; Franciaa, G. D., Calibrating chemical multisensory devices for real world applications: An in-depth comparison of quantitative machine learning approaches. Sensors and Actuators B: Chemical 2018, 255, 1191-1210.

23. Bigi, A.; Mueller, M.; Grange, S. K.; Ghermandi, G.; Hueglin, C., Performance of $\mathrm{NO}, \mathrm{NO}_{2}$ low cost sensors and three calibration approaches within a real world application. Atmos. Meas. Tech. 2018, 11, 3717-3735.

24. Smith, K. R.; Edwards, P. M.; Ivatt, P. D.; Lee, J. D.; Squires, F.; Dai, C.; Peltier, R. E.; Evans, M. J.; Sun, Y.; Lewis, A. C., An improved low-power measurement of ambient $\mathrm{NO}_{2}$ and $\mathrm{O}_{3}$ combining electrochemical sensor clusters and machine learning. Atmos. Meas. Tech. 2019, 12, 1325-1336.

25. De Vito, S.; Piga, M.; Martinotto, L.; Francia, G. D., CO, $\mathrm{NO}_{2}$ and $\mathrm{NO}_{\mathrm{x}}$ urban pollution monitoring with onfield calibrated electronic nose by automatic bayesian regularization. Sens. Actuat. B-Chem. 2009, 143, 182-191.

26. Esposito, E.; Vito, S. D.; Salvato, M.; Bright, V.; Jones, R.; Popoola, 0., Dynamic neural network architectures for on field stochastic calibration of indicative low cost air quality sensing systems. Sens. Actuat. B-Chem. 2016, 231, 701-713.

27. Spinelle, L.; Gerboles, M.; Villani, M. G.; Aleixandre, M.; Bonavitacola, F., Field calibration of a cluster of low-cost available sensors for air quality monitoring. Part A: Ozone and nitrogen dioxide. Sensors and Actuators B: Chemical 2015, 215, 249-257.

28. Cross, E. S.; Williams, L. R.; Lewis, D. K.; Magoon, G. R.; Onasch, T. B.; Kaminsky, M. L.; Worsnop, D. R.; Jayne, J. T., Use of electrochemical sensors for measurement of air pollution: correcting interference response and validating measurements. Atmos. Meas. Tech. 2017, 10, 3575-3588.

29. Hagler, G. S. W.; Williams, R.; Papapostolou, V.; Polidori, A., Air Quality Sensors and Data Adjustment Algorithms: When Is It No Longer a Measurement? Environ. Sci. Technol. 2018, 52 (10), 5530-5531. 
30. Schalenbach, M.; Hoefner, T.; Paciok, P.; Carmo, M.; Lueke, W.; Stolten, D., Gas Permeation through Nafion. Part 1: Measurements. J. Phys. Chem. C 2015, 119 (45), 25145-25155.

31. Alphasense Ltd. Environmental changes: temperature, pressure, humidity, Tech. Rep. AAN 110, Great Notley, UK, http://www.alphasense.com/WEB1213/wpcontent/uploads/2013/07/AAN 110.pdf.
32. Pang, X.; Shaw, M. D.; Lewis, A. C.; Carpenter, L. J.; Batchellier, T., Electrochemical ozone sensors: A miniaturised alternative for ozone measurements in laboratory experiments and air-quality monitoring. Sens. Actuat. B-Chem. 2017, 240, 829837. 


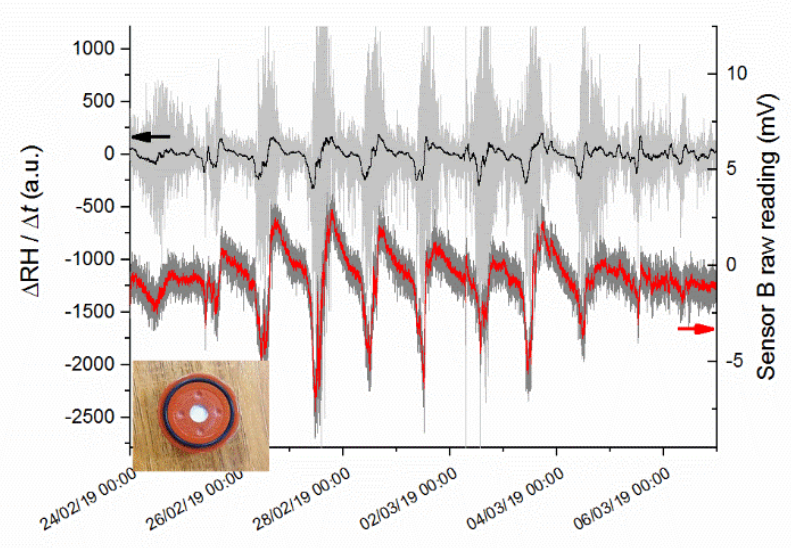

Electrochemical $\mathrm{NO}_{2}$ sensor covered by Nafion membrane to directly monitor sensor response to relative humidity transients 